\title{
Metal Exchange and Diffusion during Atomic Layer Deposition of Cobalt and Nickel Sulfides
}

Jiahao Zhu, ${ }^{\mathrm{a}, \mathrm{b}}$ Ran Zhao, ${ }^{\mathrm{a}}$ Jianmin Shi, ${ }^{\mathrm{c}}$ Qingbo Wa, ${ }^{\mathrm{a}}$ Min Zhang, ${ }^{\mathrm{b}}$ and Xinwei

\author{
Wanga,*
}

a School of Advanced Materials, Shenzhen Graduate School, Peking University, Shenzhen 518055, China

${ }^{\mathrm{b}}$ School of Electronic and Computer Engineering, Shenzhen Graduate School, Peking University, Shenzhen 518055, China

${ }^{\mathrm{c}}$ Institute of Nuclear Physics and Chemistry, China Academy of Engineering Physics, Mianyang 621000, China

*Corresponding email: wangxw@pkusz.edu.cn 
Thermodynamic analysis of the reaction:

(1) $\mathrm{CoS}_{0.89}+\mathrm{Ni}(\text { amd })_{2} \rightarrow \mathrm{NiS}_{0.89}+\mathrm{Co}(\text { amd })_{2}$

$\Delta G_{1}$

Reaction (1) can be viewed as a combination of Reactions (2) and (3).

(2) $\mathrm{CoS}_{0.89}+\mathrm{Ni} \rightarrow \mathrm{NiS}_{0.89}+\mathrm{Co}$

$\Delta G_{2}$

(3) $\mathrm{Co}+\mathrm{Ni}(\text { amd })_{2} \rightarrow \mathrm{Co}(\text { amd })_{2}+\mathrm{Ni}$

$\Delta G_{3}$

For Reaction (2), $\Delta G_{2}=8.995 \mathrm{~kJ} / \mathrm{mol}$, as the standard Gibbs free energies of formation were $\Delta G_{\mathrm{f}}^{0}\left(\mathrm{NiS}_{0.89}\right)=-83.693 \mathrm{~kJ} / \mathrm{mol}$ and $\Delta G_{\mathrm{f}}^{0}\left(\mathrm{CoS}_{0.89}\right)=-92.688$ $\mathrm{kJ} / \mathrm{mol}^{1,2}$

For Reaction (3), $\Delta G_{3}$ can be estimated from the reduction potentials of $\mathrm{Co}(\mathrm{amd})_{2}$ and $\mathrm{Ni}(\mathrm{amd})_{2}$ as follows. As shown in Figure S1, the reduction potentials of $\mathrm{Co}(\mathrm{amd})_{2}$ and $\mathrm{Ni}(\mathrm{amd})_{2}$ were measured by cyclic voltammetry in $0.1 \mathrm{~mol} / \mathrm{L} \mathrm{Bu}_{4} \mathrm{NPF}_{6}$ in $\mathrm{CH}_{2} \mathrm{Cl}_{2}$, with a standard three-electrode system using glassy carbon working and counter electrodes and $\mathrm{Ag} / \mathrm{Ag}^{+}$reference electrode $\left(0.01 \mathrm{~mol} / \mathrm{L} \mathrm{AgNO}_{3}\right.$ in $\left.\mathrm{CH}_{3} \mathrm{CN}\right)$. The silver pseudo-reference electrode was calibrated by the ferrocene/ferrocenium $\left(\mathrm{Fc} / \mathrm{Fc}^{+}\right)$ reference redox system. The cyclic voltammetry was performed between $-1 \mathrm{~V}$ and $0 \mathrm{~V}$ vs. $\mathrm{Ag} / \mathrm{Ag}^{+}$at a scan rate of $10 \mathrm{mV} / \mathrm{s}$.

(4) $\mathrm{Co}(\mathrm{amd})_{2}+2 \mathrm{e}^{-} \rightarrow \mathrm{Co}+2$ (amd)

$E=-0.712 \mathrm{~V}$ vs. $\mathrm{Fc} / \mathrm{Fc}^{+}$

(5) $\mathrm{Ni}(\mathrm{amd})_{2}+2 \mathrm{e}^{-} \rightarrow \mathrm{Ni}+2$ (amd $)^{-}$

$E=-0.668 \mathrm{~V}$ vs. $\mathrm{Fc} / \mathrm{Fc}^{+}$

Combining Reactions (4) and (5) gives $\Delta E=0.044 \mathrm{~V}$ for Reaction (3), and therefore $\Delta G_{3}=-n F \Delta E=-8.5 \mathrm{~kJ} / \mathrm{mol}$.

Hence, $\Delta G_{1}=\Delta G_{2}+\Delta G_{3}=0.5 \mathrm{~kJ} / \mathrm{mol}$, which is fairly small. Therefore, Reaction (1) can easily proceed by pumping away the $\mathrm{Co}(\mathrm{amd})_{2}$ product.
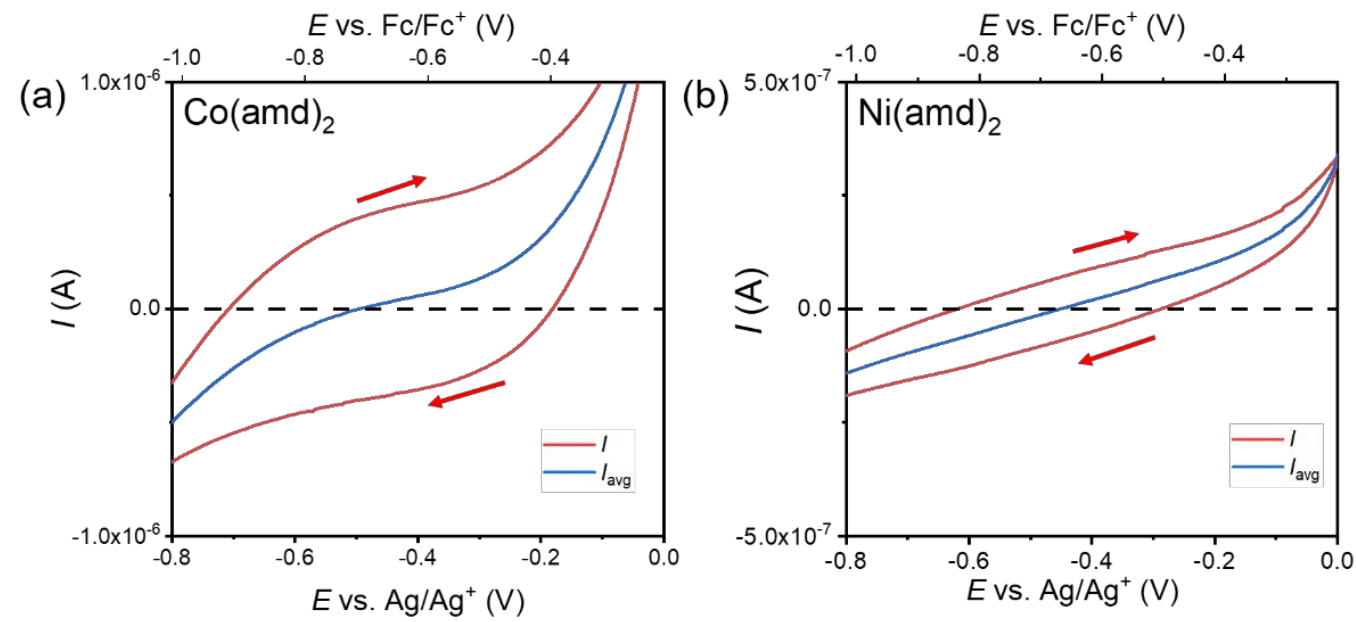

Figure S1. Cyclic voltammetry curves of (a) $\mathrm{Co}(\mathrm{amd})_{2}$ and (b) $\mathrm{Ni}(\mathrm{amd})_{2}$. The averaged current of the cathodic and anodic scans is denoted as $I_{\text {avg, }}$ which removes the effect from electrical double-layer capacitance. 

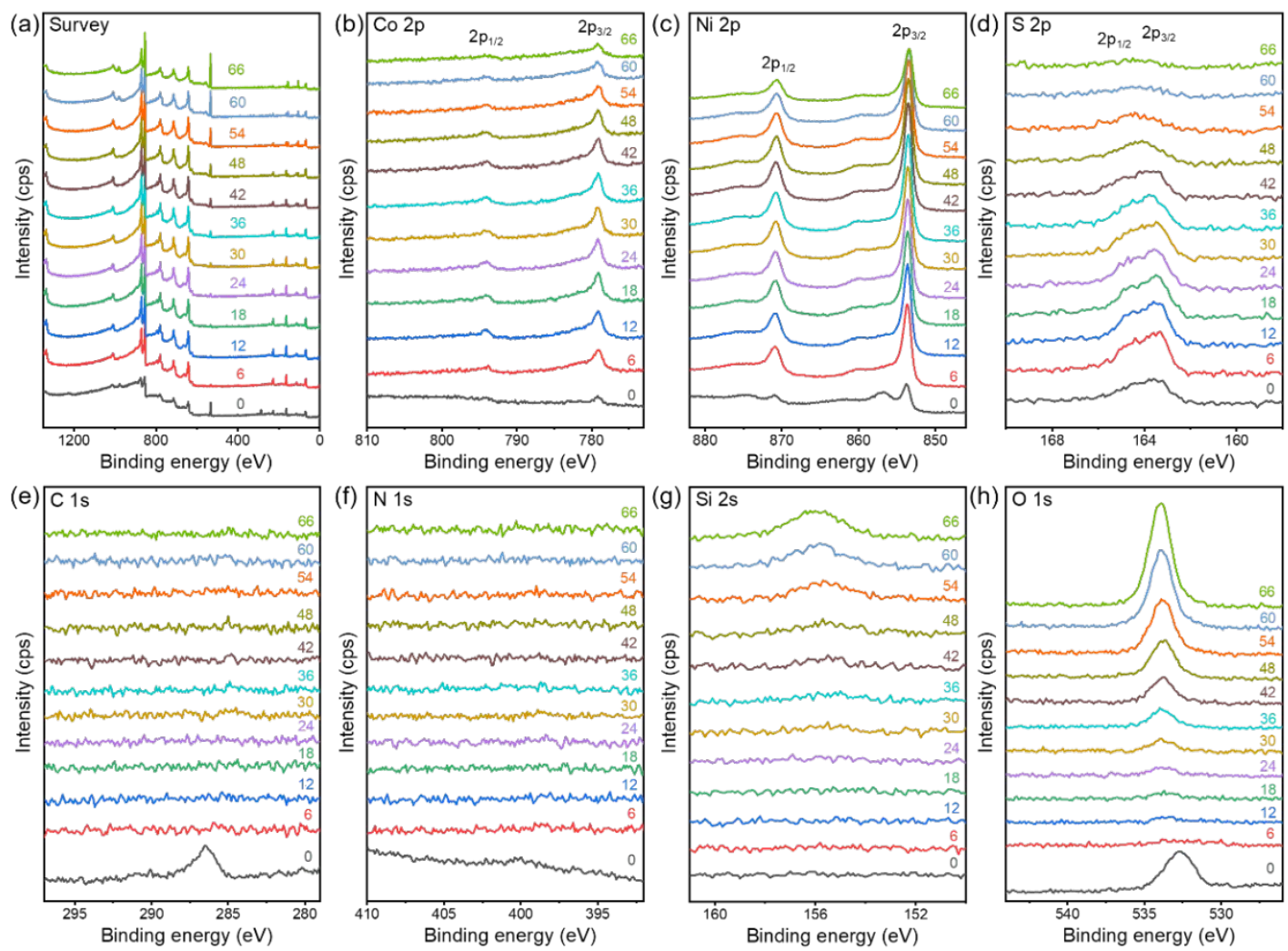

Figure S2. Ex situ depth profiling XPS spectra of the Ni(amd) $)_{2}$-treated $\mathrm{CoS}_{0.89}$ film $\left(200{ }^{\circ} \mathrm{C}\right.$ ): (a) survey and high-resolution (b) Co $2 \mathrm{p}$, (c) Ni 2p , (d) S 2p, (e) C 1s, (f) N $1 \mathrm{~s}$, (g) $\mathrm{Si} 2 \mathrm{~s}$, and (h) $\mathrm{O} 1 \mathrm{~s}$ spectra. The numbers above the curves indicate the corresponding ion sputtering times (unit in second).

Table S1. XRF results of the pure $\mathrm{CoS}_{0.89}$ film and the Ni(amd) $)_{2}$-treated $\mathrm{CoS}_{0.89}$ film $\left(200{ }^{\circ} \mathrm{C}\right)$.

\begin{tabular}{cccc}
\hline Sample & $\begin{array}{c}\mathbf{C o} \\
\left(\mathbf{n m o l} / \mathbf{c m}^{2}\right)\end{array}$ & $\begin{array}{c}\mathbf{N i} \\
\left(\mathbf{n m o l} / \mathbf{c m}^{2}\right)\end{array}$ & $\begin{array}{c}\mathbf{S} \\
\left(\mathbf{n m o l} / \mathbf{c m}^{2}\right)\end{array}$ \\
\hline Pure $\mathrm{CoS}_{0.89}$ film & $42 \pm 2$ & 0 & $38 \pm 2$ \\
\hline Ni(amd) $)_{2}$-treated $\mathrm{CoS}_{0.89}$ film & $7 \pm 1$ & $36 \pm 2$ & $38 \pm 2$ \\
\hline
\end{tabular}




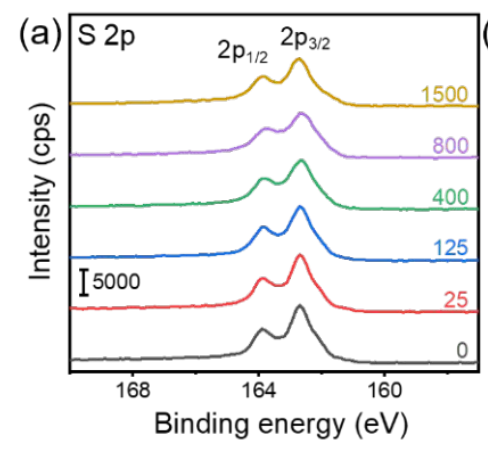

(d)
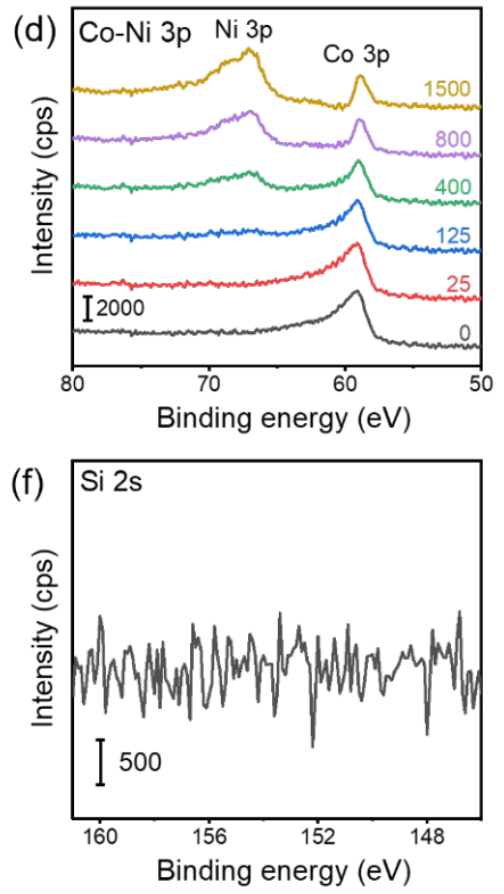
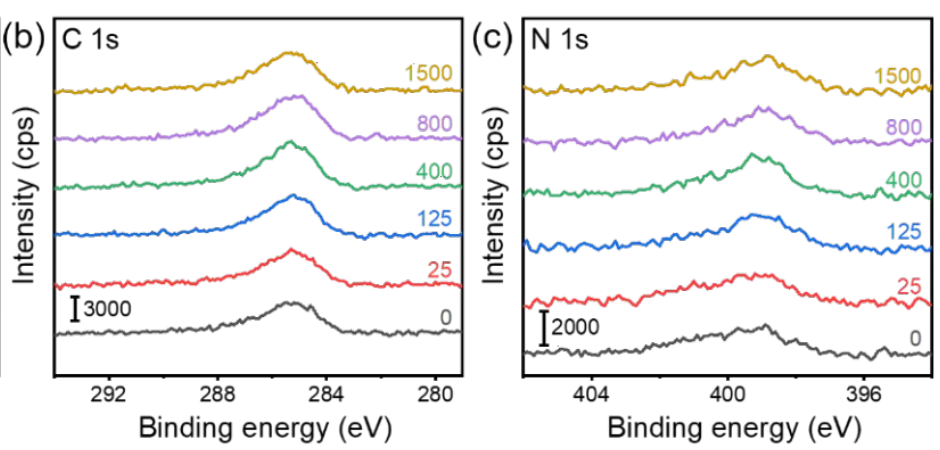

(e)

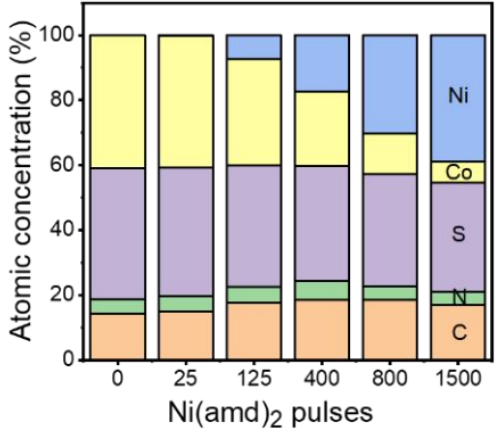

(g)

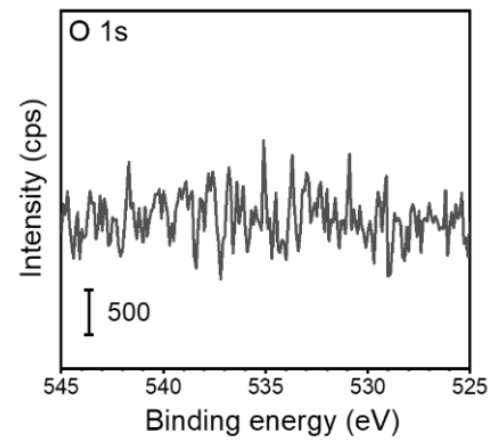

Figure S3. Additional in situ XPS results of the $\mathrm{CoS}_{0.89}$ film subjected to accumulative $\mathrm{Ni}$ (amd) 2 pulsing treatment at $200{ }^{\circ} \mathrm{C}$. (a) $\mathrm{S} 2 \mathrm{p}$, (b) C $1 \mathrm{~s}$, (c) $\mathrm{N} 1 \mathrm{~s}$, and (d) Co-Ni $3 p$ XPS spectra, and (e) stacked bar chart of atomic concentration. The numbers above curves indicate the corresponding accumulated pulse numbers. (f) $\mathrm{Si} 2 \mathrm{~s}$ and (g) O 1s XPS spectra for the initial surface (i.e. pulse number $=0$ ). 


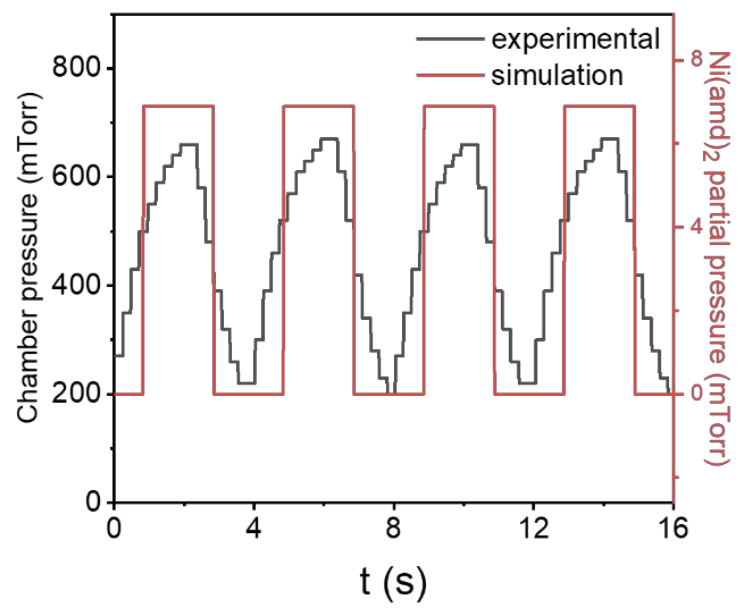

Figure S4. Traces of (black) the measured chamber pressure and (red) the approximated rectangular-wave function of $P(t)\left(\mathrm{Ni}(\mathrm{amd})_{2}\right.$ partial pressure) as used in the simulation.
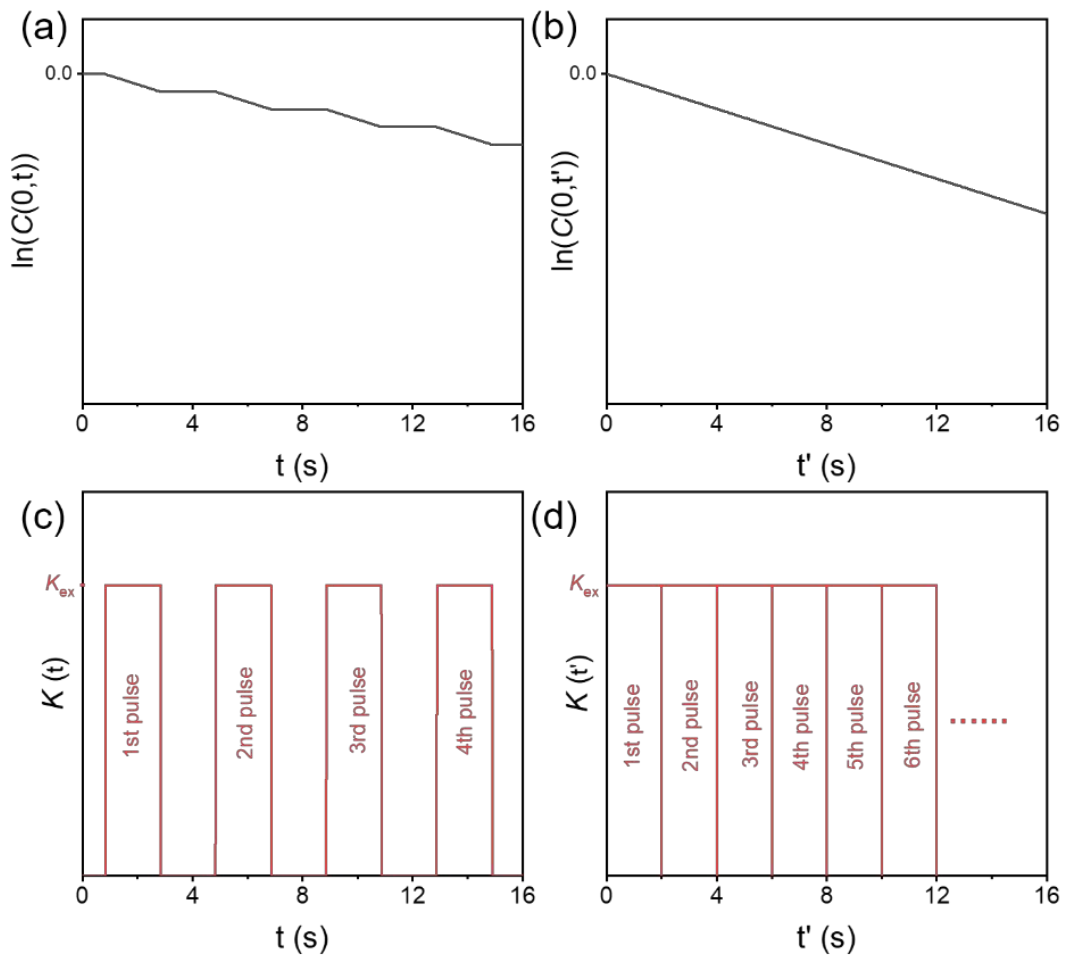

Figure S5. Under the spatial constant approximation of $C(x, t)$, no further diffusion would occur during the pulse intervals, and therefore the pulse intervals can be dropped out from the time series of $K(t)$. Equivalently, $t$ can be re-defined as $t^{\prime}$, and $K\left(t^{\prime}\right)$ becomes a constant of $K_{\mathrm{ex}}$ and $C\left(0, t^{\prime}\right)$ decays exponentially with $t^{\prime}$. 

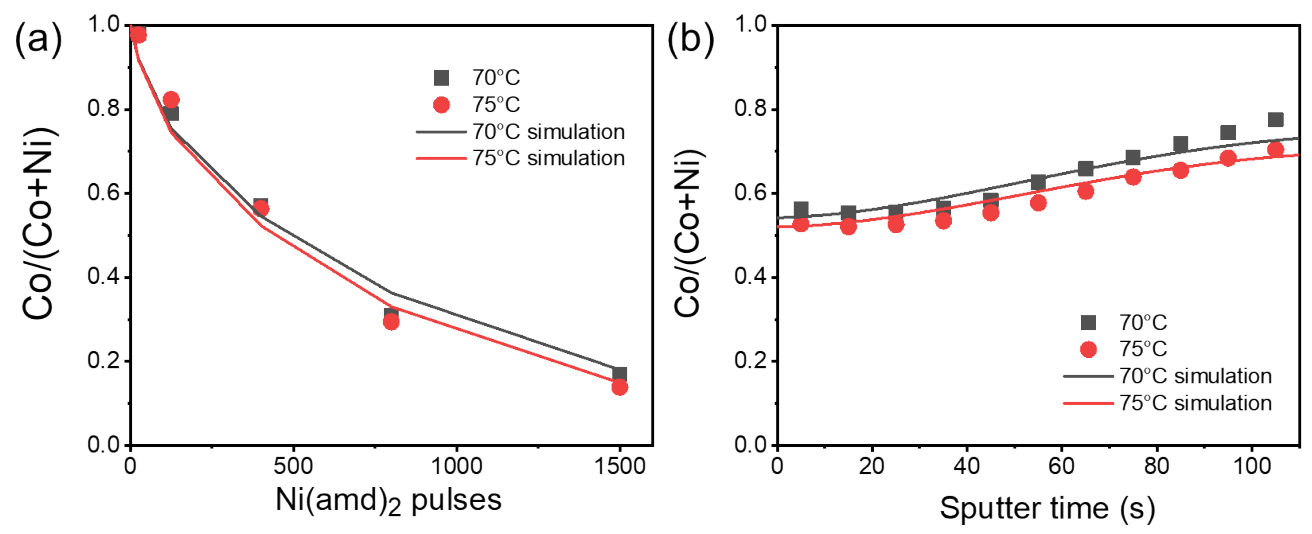

Figure S6. (a) Atomic ratio of $\mathrm{Co} /(\mathrm{Co}+\mathrm{Ni})$ obtained from the in situ XPS measurements on the $\mathrm{CoS}_{0.89}$ film subjected to accumulative $\mathrm{Ni}(\mathrm{amd})_{2}$ pulsing treatment at $200{ }^{\circ} \mathrm{C}$. (b) Atomic ratio of $\mathrm{Co} /(\mathrm{Co}+\mathrm{Ni})$ obtained from the in situ XPS depth profiling on the $\mathrm{CoS}_{0.89}$ film after $400 \mathrm{Ni}(\mathrm{amd})_{2}$ pulses. The labeled temperatures $\left(70{ }^{\circ} \mathrm{C}\right.$ and $\left.75{ }^{\circ} \mathrm{C}\right)$ refer to the heating temperatures of the $\mathrm{Ni}(\mathrm{amd})_{2}$ container. According to reference, ${ }^{3}$ elevating the $\mathrm{Ni}(\text { amd })_{2}$ heating temperature from $70{ }^{\circ} \mathrm{C}$ to $75^{\circ} \mathrm{C}$ can increase its vapor pressure by $10 \%$, and accordingly the partial pressure of $\mathrm{Ni}(\text { amd })_{2}$ should also increase by $10 \%$ during the pulsing treatment. The simulation curves correspond to the best fitted parameters of $K_{\text {ex }}$ and $D$, which are $5.3 \times 10^{-10} \mathrm{~cm} / \mathrm{s}\left(K_{\mathrm{ex}}\right)$ and $1.2 \times 10^{-16} \mathrm{~cm}^{2} / \mathrm{s}(D)$ for $70^{\circ} \mathrm{C}$ and $6.0 \times 10^{-10} \mathrm{~cm} / \mathrm{s}\left(K_{\mathrm{ex}}\right)$ and $1.2 \times 10^{-16} \mathrm{~cm}^{2} / \mathrm{s}(D)$ for $75^{\circ} \mathrm{C}$. The data for $70{ }^{\circ} \mathrm{C}$ are duplicated from Figure 2d,f.
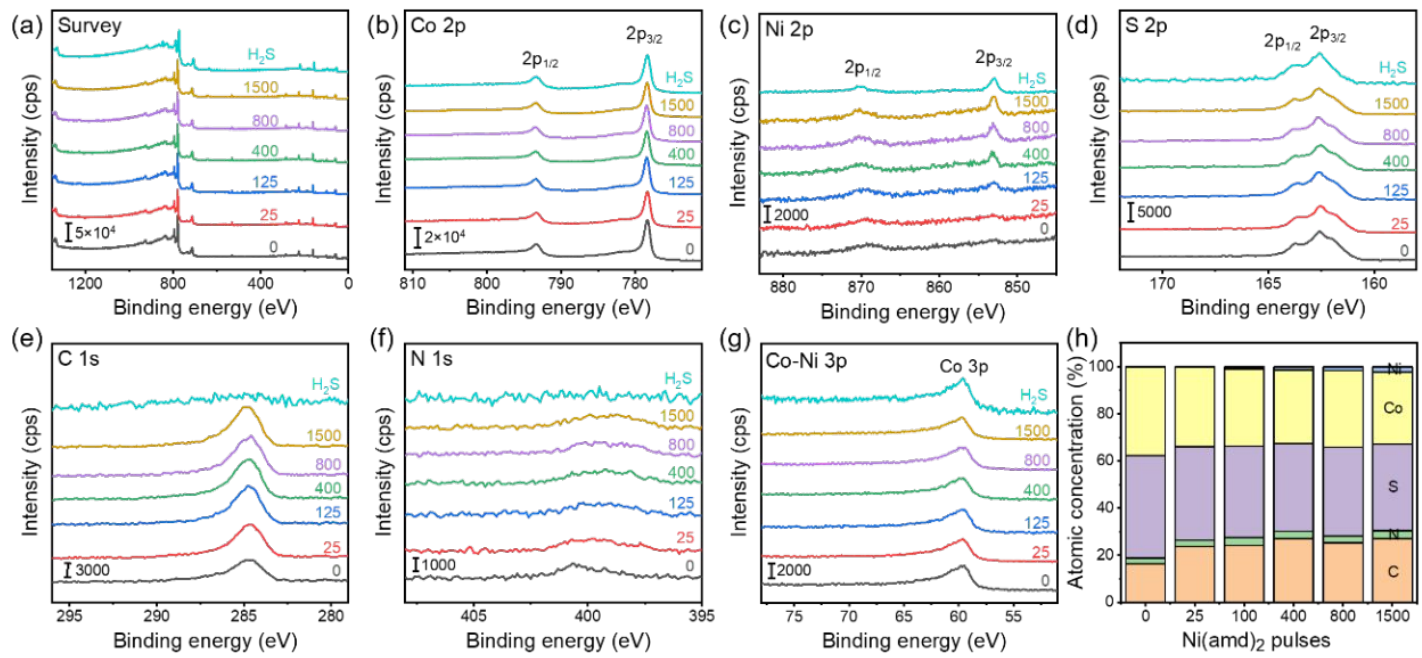

Figure S7. Additional in situ XPS results of the $\mathrm{CoS}_{0.89}$ film subjected to accumulative $\mathrm{Ni}$ (amd) $)_{2}$ pulsing treatment at $100{ }^{\circ} \mathrm{C}$ and the follow-up $\mathrm{H}_{2} \mathrm{~S}$ treatment. (a) Survey, (b) Co 2p, (c) Ni 2p, (d) S 2p, (e) C 1s, (f) N 1s, and (g) Co-Ni 3p XPS spectra, and (h) stacked bar chart of atomic concentration. The numbers above curves indicate the corresponding accumulated pulse numbers. 
(a)

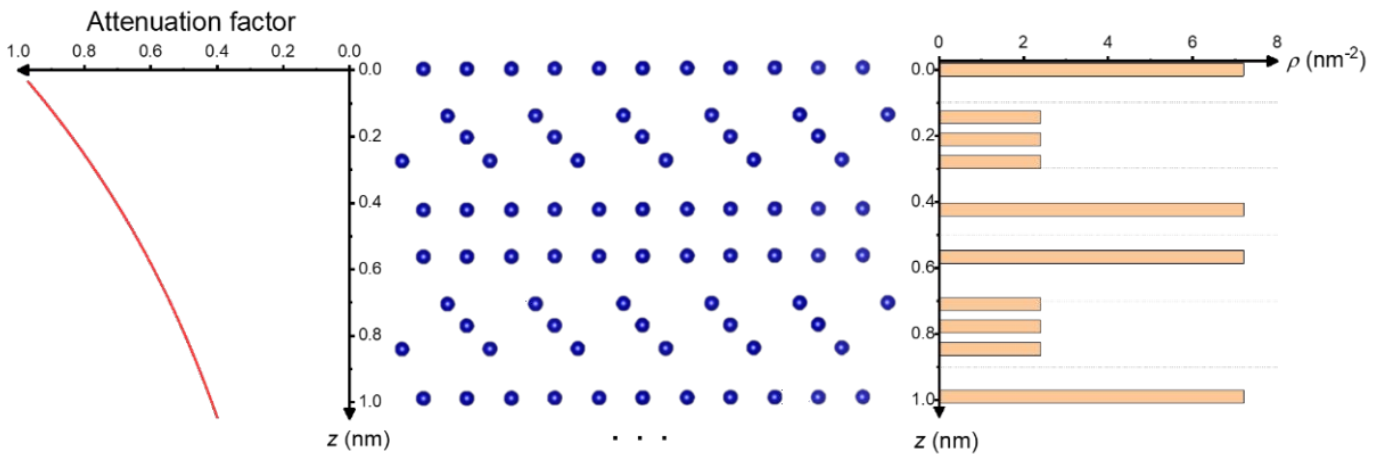

(b)

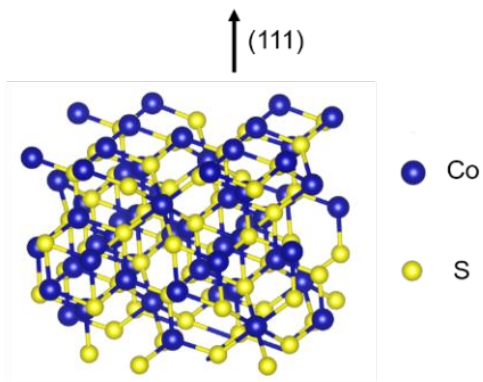

(c)

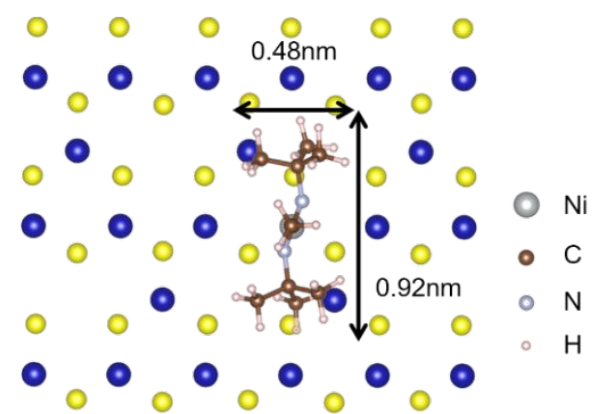

Figure S8. Estimation of the XPS $\mathrm{Co} /(\mathrm{Co}+\mathrm{Ni})$ atomic ratio induced by the submonolayer replacement of the Co atoms by $\mathrm{Ni}$ atoms on the surface.

XPS signal intensity is known to be attenuated by a capping layer. With a photoelectron takeoff angle of $90^{\circ}$ (normal to surface), the XPS signal intensity from the substrate is attenuated by a factor of $\exp (-d / \lambda)$, where $d$ is the capping layer thickness and $\lambda$ is the electron effective attenuation length, which is related to the inelastic and elastic electron scattering in the capping layer. ${ }^{4}$ For the Co $2 p$ signal studied herein, $\lambda$ is approximately $1.14 \mathrm{~nm}^{5}$

We use the Co-terminated $\mathrm{Co}_{9} \mathrm{~S}_{8}(111)$ surface as a representative model surface to estimate the XPS intensities and analyze the effect of the submonolayer Co-to-Ni replacement. Panel a shows the cross-sectional atomic arrangement of $\mathrm{Co}_{9} \mathrm{~S}_{8}$ (space group: Fm-3m), and the atomic density of Co in each atomic layer $(\rho)$ is plotted on the right with respect to the depth of the layer $(z)$ from the surface. For the topmost layer, we assume that a fraction $(a, 0 \leq a \leq 1)$ of Co atoms are replaced by Ni. Therefore, the $\mathrm{XPS} \mathrm{Co} /(\mathrm{Co}+\mathrm{Ni})$ atomic ratio can be calculated as follows:

$$
\text { XPS Co/ }(\mathrm{Co}+\mathrm{Ni})=1-\mathrm{XPS} \mathrm{Ni} /(\mathrm{Co}+\mathrm{Ni})=1-\frac{a \rho_{1}}{\sum \rho_{i} e^{-z_{i} / \lambda}}=1-0.155 a
$$

The experimental value of 0.93 (at 1500 pulses) corresponds to $a=0.45$, which suggests $45 \%$ of the top layer Co atoms were replaced by $\mathrm{Ni}$. 


\section{References}

1. Waldner, P.; Pelton, A. D., Thermodynamic modeling of the Ni-S system. $Z$. Metallkd. 2004, 95, 672-681.

2. Cl-Cu2Te. In Thermochemical Data of Pure Substances, 1995; pp 524-634.

3. Li, Z.; Gordon, R. G.; Pallem, V.; Li, H.; Shenai, D. V., Direct-LiquidInjection Chemical Vapor Deposition of Nickel Nitride Films and Their Reduction to Nickel Films. Chem. Mater. 2010, 22, 3060-3066.

4. Powell, C. J.; Jablonski, A., Electron effective attenuation lengths for applications in Auger-electron spectroscopy and x-ray photoelectron spectroscopy. Surf. Interface Anal. 2002, 33, 211-229.

5. C. J. Powell and A. Jablonski, NIST Electron Effective-Attenuation-Length Database, Version 1.3, Standard Reference Data Program Database 82, US Department of Commerce, National Institute of Standards and Technology, Gaithersburg, MD, 2011, https://www.nist.gov/srd/nist-standard-reference-database-82. 